\title{
EJEMPLOS DEL DISCURSO HOMOFÓBICO EMITIDO POR ALGUNOS SECTORES POLÍTICOS EN VENEZUELA: ARTÍCULO 21 DE LA CONSTITUCIÓN NACIONAL
}

\author{
MERY CAROLINA ANDRADES MARCANO ${ }^{1}$
}

\author{
Universidade Federal do Tocantins \\ Programa de Pós-Graduação em Letras: Ensino de Línguas e Literatura \\ Av. Paraguai, s/n Str Cimba, 77824-838 - Araguaína, TO - Brasil
}

$\underline{\text { meryandrades@hotmail.com }}$

\begin{abstract}
Resumen. El siguiente artículo es producto de las clases vistas en la asignatura Tópicos Especiales III: Análisis del discurso: teoría, método y análisis, del programa de Postgrado en Letras: enseñanza de lenguas y literatura. El objetivo principal es analizar dos ejemplos del discurso homofóbico impregnado en sectores de la sociedad venezolana. Es una investigación de tipo documental, en la cual se accedió al material analizado a través de YouTube y se fundamenta en autores como Gasparini (2015), Pereira (2007), Leite (2014), entre otros. Los resultados revelan que los discursos emanados forman parte de la realidad venezolana.
\end{abstract}

Palabras clave: discurso homofóbico; sociedad venezolana; práctica social.

Resumo. O seguinte artigo é produto das aulas cursas na disciplina Tópicos Especiais III: Análise do discurso: teoria, método e análise, do programa de Pós-graduação em Letras: ensino de línguas e literatura. O objetivo principal é analisar dos exemplos do discurso homofóbico impregnado em setores da sociedade venezuelana. É uma pesquisa de tipo documental, na qual o material analisado foi acessado a partir do YouTube e fundamenta-se em autores como Gasparini (2015), Pereira (2007), Leite (2014), dentre outros. Os resultados revelam que os discursos produzidos formam parte da realidade venezuelana.

Palavras-chave: discurso homofóbico; sociedade venezuelana; prática social.

\begin{abstract}
The following article is a product of the subject called Special Topics III: Discourse Analysis: Theory, Method and Analysis from the Post graduate Program in Arts: Language and Literature Teaching. Its main objective is to analyze two examples of the homophobic discourse impregnated in some sectors of the Venezuelan society. It is a documental
\end{abstract}

\footnotetext{
${ }^{1}$ Doutoranda em Ensino de Língua e Literatura na Universidade Federal do Tocantins.
} 
research, in which the material analyzed was taken from YouTube. It is based in authors such as Gasparini (2015), Pereira (2007), Leite (2014) and some others. The results reveal that the discourses produced are part of the Venezuelan reality.

Keywords: homophobic discourse; Venezuelan society; social practice.

\section{INTRODUCCIÓN}

En los últimos años en Venezuela se han dado una serie de cambios en los distintos niveles que conforman la sociedad. Éstos deberían ser extensivos sin ningún tipo de discriminación y en igualdad de condiciones para todas y todos. Es justamente esta diversidad en la población lo que conduce a la existencia de diferentes identidades de individuos dando lugar a la presencia de una comunidad llamada LGBTI (Lesbianas, Gays, Bisexuales, Transexuales, Intersexuales).

Esta comunidad, con estos cambios, ha intentado ser reconocida en el marco de las leyes venezolanas con el fin de contar con los mismos deberes y derechos pero ha tenido que enfrentar numerosas trabas que hasta los días actuales persisten. Esta falta de reconocimiento amplio es precisamente para luchar contra la discriminación, racismo y falta de oportunidades. Si bien, se dan estas fallas dentro de las leyes, está otra de mayor importancia que es la discriminación que ocurre por parte de la propia sociedad al ser emitidas diferentes expresiones habladas y/o escritas que conllevan a la burla, la falta de respeto y la homofobia hacia personas que son parte de la comunidad LGBTI.

A pesar de que es dicho por los propios venezolanos de que no somos racistas ni discriminadores como en otros países, es notorio observar las reacciones, a veces de manera silenciosa, al ver a una persona que no sigue los parámetros impuestos por la sociedad y las iglesias católica y cristiana. Estas reacciones son parte de un discurso que se mantiene impregnado y que produce una serie de efectos, mostrando así la realidad social y las desigualdades entre todos los sectores.

Todo ese panorama de desigualdad puede notarse en las esferas de la sociedad venezolana a través de discursos que son emitidos por personas que representan a los seres que se dicen llamar perfectos, como lo son los políticos y los medios de comunicación, que según ellos, garantizan la información veraz y la imparcialidad. Son justamente esos discursos los que serán analizados en este artículo, el cual tiene como propósito presentar dos ejemplos específicos que se produjeron en Venezuela entre los años 2013 y 2017.

Sobre la metodología utilizada es importante resaltar que este artículo se basa en una investigación de tipo documental en la que fueron accedidas las publicaciones sobre los discursos emitidos tanto en la Asamblea Nacional como en el programa radial Calma Pueblo de la emisora Mega 107.3 FM. Ambos permanecen publicados en YouTube. Como se dijo anteriormente, el primero fue emitido en el año 2013 y el segundo en el 2017, lo que denota que el discurso analizado es un discurso persistente, aun cuando desde 1999 se garantiza que el nuevo modelo de sociedad venezolana es inclusivo, igualitario y democrático. 
Este texto ha sido organizado de la siguiente manera: primero se ahonda en los fundamentos teóricos que sustentan el tema; luego, se realiza un recorrido por los cambios propiciados en la estructura política y social venezolana; seguidamente se enfatiza en el artículo 21 de la Constitución de la República Bolivariana de Venezuela (CRBV), luego en las reivindicaciones que la comunidad LGBTI exige y finalmente, en los ejemplos centrales de los sectores políticos del país que serán analizados discursivamente.

\section{FUNDAMENTOS TEÓRICOS}

El lenguaje en cualquiera de sus expresiones, ya sea un documento, texto literario, diálogo, imagen o artículo de periódico puede ser objeto de un análisis discursivo que conlleva a desglosar lo que está expresado o no en ellos y produce diferentes efectos de sentidos. Es mediante el análisis discursivo que se toma en cuenta el lenguaje en circulación o que domina dentro de un contexto determinado, pudiendo así analizar las construcciones ideológicas presentes y la coyuntura del sujeto, es decir, los acontecimientos, escenarios, actores, relaciones de fuerza y articulación entre estructura y dicha coyuntura (PEREIRA, 2007).

Según Ferreira (1998, apud LEITE, 2014, p. 418) se entiende "el discurso como un proceso de significación que toma en cuenta la materialidad histórica del lenguaje y el sujeto interpelado por la ideología", siguiendo lo dicho por Pêcheux (1969), quien establece una relación entre la lengua, el sujeto y la ideología, dándose así un mecanismo de producción de sentidos en un discurso determinado.

Por otra parte y desde una perspectiva social, Foucault (1970, apud RUIZ, 2011) señala que los discursos constituyen sistemas interrelacionados de significaciones (efectos) que producen sentido, constituyen vínculos sociales y hacen posible la práctica significante mediante el funcionamiento de la lengua, la cual es un "elemento fundamental en el abordaje de los procesos de producción de discurso" (GASPARINI, 2015, p. 65).

Es el discurso el efecto de sentidos entre los interlocutores, lo que significa que se va a producir una división desigual de ellos y el proceso de análisis discursivo generado va a interrogar a esos sentidos establecidos en las diferentes maneras en que son transmitidos, pudiendo ser éstos lingüísticos o no lingüísticos. Esto quiere decir, que la lengua va deslizando esos sentidos en la medida en que son producidos por los emisores y que sin duda, tienen diferentes significados que influyen en los receptores dentro de determinado proceso discursivo.

Así pues, son originadas formaciones discursivas que son el reflejo de manifestaciones concretas del habla en relación a diferentes situaciones que se desarrollan en la sociedad. Según Ruiz (2011) el discurso posee también intención política y cobra su carácter político a medida que circula masivamente y se deriva del imaginario social, estando presente en él y es constituyente de los sentidos. Esa circulación masiva permite entender el discurso como una práctica social y esas creaciones culturales son el reflejo del mundo material y forman parte de la materialidad del mundo (STECHER; STECHER, 2010).

Esos discursos de acuerdo con Santander (2011) constituyen una base empírica más certera que la introspección racional, es decir, son enunciados que se mantienen en 
constante movimiento y llegan a ser observables, lo que permite que sean analizados socialmente concibiéndose como una forma de acción. Por lo tanto, se entiende que todo evento discursivo tiene efectos políticos e ideológicos, en la medida que es parte constitutiva de prácticas sociales que cotidianamente producen, sostienen o transforman las relaciones de dominación que imperan en una sociedad.

En este artículo se discute justamente dos situaciones que pudiesen reflejar esos discursos como una práctica social (FAIRCLOUGH, 1992, 1995 apud SANTANDER 2011) como forma de demostrar la materialidad del lenguaje que se produce y circula dentro de la sociedad. Muestra de ellos son los ejemplos que se verán más adelante, los cuales remeten a un acontecimiento político y el otro de un medio de comunicación. Ambos manejan contenido social que impacta en las masas y que tienen repercusiones o consecuencias en los receptores de ambos mensajes.

\section{PANORAMA VENEZOLANO ANTES Y DESPUÉS DE 1999}

Según datos de la Comisión Económica para América Latina y el Caribe, Venezuela, para el año 1999, estaba sumergida en un atraso social y económico con una pobreza que alcanzaba el 49,4\% (CEPAL, 2016) y un sistema gubernamental conducido por la burguesía venezolana, que a su vez no beneficiaba a las clases más necesitadas con los ingresos provenientes del petróleo, sino que fueron históricamente olvidados, creciendo cada vez más la brecha entre ricos.

En este panorama el ciudadano venezolano desconocía sus derechos y deberes. La democracia era representativa y no existía la participación directa de la gente en las decisiones que eran tomadas por el gobierno central, lo que generaba falta de conocimiento e interés por parte de la población hacia el funcionamiento del sistema político venezolano. Un grupo reducido de personas se manifestaba durante el periodo electoral para elegir a los "representantes", siendo los índices de abstención elevados, ya que le era dado poco sentido al sufragio y serían olvidados por quienes fueran elegidos y cuyas políticas públicas profesadas durante las campañas no serían cumplidas. Podemos ver en este caso que ese discurso político emanado por los gobernantes de turno causaba una serie de efectos negativos en la población y gracias a las circunstancias que se vivían, no se creía que la situación mejoraría.

A finales de 1998 fueron realizadas las elecciones presidenciales en las que resultó ganador un teniente coronel llamado Hugo Chávez que mantuvo su discurso político justamente enmarcado dentro de un padrón social común para la mayoría de la población. Seguramente por sus orígenes humildes y sus vivencias similares con personas de clase baja contribuyeron a que este tipo de discurso calara en el venezolano de a pie que cada día vivía las penurias en las que estaba sometido el país.

Es a partir de aquí que Venezuela tiene cambios fundamentales en su estructura política, económica, social e ideológica y se pudo notar la influencia de ese discurso nuevo en la vida del ciudadano venezolano, haciéndolo una persona consciente y con voluntad de participar en todo el proceso de mudanza que ocurría en Venezuela en ese entonces. Se eligió meses después, una Asamblea Nacional Constituyente y fue aprobada una nueva 
constitución (actualmente vigente), la cual contempla una serie de reformas fundamentales en el país.

Una de esas reformas, está relacionada directamente con la comunidad LGBTI, que mediante el artículo 21 de la nueva carta magna pudiese estar representada. El mismo garantiza la no discriminación de personas por su condición sexual, raza, credo, etc., tal como dice textualmente.

Todas las personas son iguales ante la ley; en consecuencia: 1. No se permitirán discriminaciones fundadas en la raza, el sexo, el credo, la condición social o aquellas que, en general, tengan por objeto o por resultado anular o menoscabar el reconocimiento, goce o ejercicio en condiciones de igualdad, de los derechos y libertades de toda persona. 2. La ley garantizará las condiciones jurídicas y administrativas para que la igualdad ante la ley sea real y efectiva; adoptará medidas positivas a favor de personas o grupos que puedan ser discriminados, marginados o vulnerables; protegerá especialmente a aquellas personas que por alguna de las condiciones antes especificadas, se encuentren en circunstancia de debilidad manifiesta y sancionará los abusos o maltratos que contra ellas se cometan. 3. Sólo se dará el trato oficial de ciudadano o ciudadana, salvo las fórmulas diplomáticas. 4. No se reconocen títulos nobiliarios ni distinciones hereditarias. (CRBV, 1999, p.162)

Aquí queda explícito legalmente que no se permitirá ninguna discriminación fundamentada en raza, sexo, credo o religión o la condición social de las personas, con el fin de garantizar que sean reconocidas dentro de la sociedad y que puedan tener los derechos, deberes y libertad como cualquier otra y que en caso de que esto suceda, las leyes de la República serán accionadas para garantizar la igualdad entre todos. Sin embargo, serán presentados más adelantes dos ejemplos que evidencian que este artículo no se cumple, ya que persiste un discurso discriminatorio por parte de algunos sectores de la población.

No se puede negar que en Venezuela se han dado pasos agigantados en materia de ciudadanía, pero también es importante resaltar que aún existen ciertos aspectos en los cuales no se han avanzado como es el caso de la comunidad LGBTI. En este sentido, más de 20 países como Brasil, España, Colombia, Holanda, entre otros, representan un ejemplo de legalidad en cuanto a los deberes y derechos de esta comunidad, lo que pudiese significar una forma de revertir todo el sufrimiento recibido por parte de una sociedad conservadora, que bajo el principio de la "moral" y las "buenas costumbres" se vuelve discriminatoria, racista y llena de prejuicios que conllevan a clasificar y desprestigiar a las personas que no cumplen con ciertos parámetros impuestos.

El hecho de ejecutar acciones a favor de la comunidad LGBTI es un esfuerzo por tratar de igualarla ante el resto de la sociedad para que quienes la conforman puedan hacer sus vidas como cualquier otra persona dentro de determinado lugar y no ser objeto de burlas, discriminación y malos tratos. 


\section{COMUNIDAD LGBTI EN VENEZUELA}

En Venezuela tales derechos y deberes establecidos en el artículo 21 no se cumplen. Existe un discurso impregnado en la sociedad avalado por la iglesia católica y otras religiones que promulgan que la familia es la base central de la sociedad y que ésta debe ser conformada por madre, padre e hijos, produciendo así actitudes de rechazo y discriminación hacia las minorías sexuales, hacia lo diferente.

Por otra parte, está el discurso gubernamental que fomenta la igualdad en todos los sectores de la sociedad venezolana, pero realmente no ha agilizado los trámites por el reconocimiento estatal y social a esta comunidad. A pesar de eso, el pasado 10 de junio de 2017, el Tribunal Supremo de Justicia aceptó un recurso interpuesto por varios ciudadanos que exigen su derecho de cambio de género y nombre en sus documentos de identidad.

Esta intencionalidad no se ha concretado del todo por temor a alejarse de las "reglas moralistas" que han sido establecidas a lo largo de los años y también, está la otra parte que requiere de modificaciones en la Constitución Nacional, el Código Civil y otras leyes venezolanas.

Dentro de las reivindicaciones que la comunidad LGBTI exige están:

- el derecho a la vida, ya que entre mayo del 2013 y mayo del 2015 se registraron 47 crímenes de odio por orientación sexual, identidad de género y expresión de género.

- el derecho a la identidad de las personas que se autodefinen como transexuales o transgéneros, siendo ellas las más vulnerables dentro de la sociedad al serle negados alimentos, oportunidades de estudios y trabajo, entre otros.

- derecho a las uniones civiles entre personas del mismo sexo para que puedan heredar o tener bienes, pólizas de seguros, etc.

- derecho a la salud, puesto que no es permitido que sean donantes de sangre.

- derecho al trabajo, ya que muchas veces se les niega por su condición y finalmente,

- derecho a que sean respetados en lugares públicos como parques, restaurantes, centros comerciales donde generalmente son discriminados por demostrar algún tipo de afecto entre ellos.

Es importante puntualizar que a pesar de haberse realizado pocos debates en algunos sectores de la sociedad sobre esta comunidad LGBTI, no se ha tomado en cuenta el reconocimiento social y legal de ella y solo existe un discurso lleno de promesas por aquellos que se asustan por romper este paradigma de la "moral" y las "buenas costumbres" y que, sin lugar a dudas, incentivan la homofobia, el irrespeto y la burla hacia estas personas, sin percibir que actualmente existe un cierto despertar que pide a gritos que esta situación no siga siendo ignorada.

Tal como fue mencionado anteriormente en el artículo 21 de la constitución venezolana, aún existen diferentes discursos homofóbicos tanto del sector gubernamental como también de algunos medios de comunicación, que claramente forman parte de la oposición venezolana, tal como lo veremos seguidamente. 


\title{
EJEMPLOS DEL DISCURSO HOMOFÓBICO EN VENEZUELA
}

A continuación serán expuestos dos casos reales. El primero sucedió en agosto del 2013 y el último en septiembre del 2017. Ambos casos causaron cierta notoriedad dentro de la población. Dentro de este periodo de 4 años el mismo discurso continua latente, lo que significa que este discurso discriminatorio y machista persiste dentro de la sociedad.

\section{Caso 1}

El 13 de agosto del 2013 el diputado oficialista Pedro Carreño (P.C), ejerciendo su derecho de palabra hace mención a un comentario colocado en la cuenta de Twitter por el gobernador, en ese momento, del estado Miranda Henrique Capriles Radonski (H.C.R). En el mismo H.C.R alega que el diputado había sido despedido de la FANB (Fuerza Armada Nacional Bolivariana) por estafa agravada, a lo que P.C lo retó a presentar pruebas en el plazo de un mes sobre el caso y por otro lado, mostró documentos contundentes sobre la sexualidad de H.C.R. A continuación se presentan los extractos más notorios de su discurso de 9 minutos y 17 segundos en el seno de la Asamblea Nacional.

\begin{abstract}
"El candidato de la derecha, el candidato perdedor publica en su Twitter 'Corrupción Roja es que Pedro Carreño haya sido botado de la FANB por estafa agravada' y coloca su cuestión.

Yo estoy seguro, compatriotas, que cualquiera pudiera creer que eso es verdad y yo le respondí sencillito aquí y le puse: "Mira vago, te lanzo un reto... si tú en un mes presentas una prueba, yo renuncio a la diputación y si no tú a la gobernación".

"Ustedes saben que respondió ese malandro, porque no tiene otra connotación y me disculpan....mariposón, petimetres y lechuginos $^{2}$ les decía Henry Ramos, o sea que ya sabía por los caminos que andaba Acción Democrática ${ }^{3}$, ya sabía en que andaba Primero Justicia. Aquí respondió: “Águilas no caza mosca”...primero, que falta de originalidad cuando es una palabra, una frase de nuestro Comandante infinito, pero segundo, él tiene que responderle al país porque él hizo una acusación...

En las fiestas rave ${ }^{4}$ de este malandro Oscar López Colina, aquí están las facturas, aquí están. El problema no es la inclinación sexual, el problema es que tienes una vida oculta y la vida privada de los hombres públicos deja de ser privada cuando impacta al colectivo y surge una interrogante entonces: ¿Qué pasará con estas personas que llevan una vida oculta en el manejo de los asuntos públicos? Por eso es que hay que desenmascararlas, desenmascararlas esas personas para que no sigan en el manejo de los asuntos públicos y es tan grave, es tan grave el caso que el mismo candidato de la derecha...aquí hay un acta policial, de un policía inspector jefe Teodoro Hernández, que hay que protegerlo, que consiguió el día 8 de mayo del 2000 , voy a leer textualmente, hay que leer textualmente: 'al llegar al sitio en la parte trasera se encontraban dos ciudadanos cometiendo actos inmorales en la vía pública (sexo oral). Uno llamado Armando y el otro plenamente identificado como Henrique Capriles Radonski'...
\end{abstract}

\footnotetext{
${ }^{2}$ Palabras despectivas que hacen referencia a la inclinación sexual de alguien y a la obsesión de vestirse a la moda.

${ }^{3}$ Acción Democrática y Primero Justicia son partidos políticos de oposición al gobierno actual de Venezuela.

${ }^{4}$ Las fiestas rave son fiestas clandestinas que surgieron a finales de los años 80 , pero en el contexto venezolano se vincula la realización de estas fiestas con hechos de droga y prostitución.
} 
Nosotros en la revolución, nosotros aceptamos la sexo diversidad, en el polo patriótico hay sexo diversos. Ese es problema de ellos lo que hagan con su culo pero tienen que ser serios, tienen que ser serios...

Pero es que este homosexual, mira lo que responde este homosexual, dice "águila no caza moscas"... lo responde homosexual, hay que decirle... acepta el reto maricón, acepta el reto, hay que ser serio".

Después de varios minutos el enunciador comienza a atacar verbalmente a su contrincante como forma de defenderse ante la falsa denuncia en su contra. Los interlocutores parecen escuchar con atención: algunos se ríen, otros se espantan y otros se quedan callados. Vale la pena resaltar que este mensaje también fue transmitido por televisión y dividió opiniones en la sociedad, es decir, los que concordaron y los que creyeron que era una falta de respeto hacia la comunidad LGBTI. El interlocutor, a su vez, demuestra ser una persona correcta al mostrar pruebas concretas y profiere palabras despectivas tales como homosexual y maricón que contienen una gran carga de negatividad ante una persona que posee esta condición. En cuanto a la pregunta, el interlocutor da a entender que personas que tengan una condición sexual diferente no pueden tener cargos públicos porque su vida privada estaría en juego. Utiliza la palabra serio dando a entender que los heterosexuales sí lo son y los homosexuales no.

Es contradictorio que el diputado P.C señale en esta misma exposición que el problema no es su inclinación sexual sino la falta de seriedad al utilizar una red social para hacer acusaciones sin pruebas, lo que pudiera verse como una contradicción. Después de todo esto, el diputado Pedro Carreño pidió disculpas públicas al producirse ciertas manifestaciones de la comunidad LGBTI exigiendo respeto y rectificación de sus palabras.

\section{Caso 2}

Otro caso de homofobia ocurrió el 18 septiembre del 2017 en una emisora de radio de Caracas (Mega 107.3 FM). Un niño de 7 años fue sometido al escarnio público por parte de la locutora Verónica Gómez Pino, plenamente opositora al gobierno, preguntándole, entre otras cosas, si sería como Messi o como Cristiano Ronaldo cuando fuera grande. En el desarrollo de la conversación, la locutora le hace preguntas al niño con contenido político para saber si él era opositor o chavista, o si cuando creciera quisiera tener bigotes, haciendo alusión a Nicolás Maduro. Inicialmente le hizo preguntas sobre la falta de gasolina en el estado Nueva Esparta, específicamente en Margarita. A continuación el extracto de la conversación en la que interviene otro locutor que percibe que las preguntas de la locutora no son adecuadas para un niño de esa edad, mientras el otro locutor se ríe placenteramente de la situación. Se puntualizan las preguntas de ella y las respuestas del niño.

Locutora: ¿Hay colas horribles para poner gasolina?

Niño: Ujum!

Locutora: Alejandro, ¿Y qué te parece eso a ti viniendo de un país petrolero?

Niño: No sé...

Locutora: Ahhh perfecto porque tú no entiendes para saber de eso.

Locutor: Usted es un niño muy inteligente porque cuando uno no sabe algo, uno dice no sé, no inventa porque inventar queda peor. Te quería hacer una pregunta, Alejandro...¿¿Qué llevas de desayuno? 
Niño: Tequeños.

Locutora: Ufff...no vale pero qué niño tan increíble.

Locutor: Mamá y papá fueron pa' un matrimonio fin de semana?...

Locutora: el primer día...mañana le manda una arepa envuelta en servilleta.

Locutor: tequeño recalenta'o después de una boda no es buena idea, por favor padres.

Locutora: Ale ¿Cuál es tu desayuno favorito para llevar al colegio?

Niño: Cualquiera...

Locutora: Mira, Ale...quiero hacerte una pregunta..._Cuándo seas grande quieres tener bigotes?

Niño: Sí...

Locutora: Ahhh como Maduro. ;Muy bien! Ahhh como Manuel...

Locutor: Como Manuel...dale buenas imágenes al niño.

Locutora: Mira, Alejandro, ¿Cuál es tu postura política? ¿Tú eres opositor o eres oficialista?

Locutor: Deja al niño Verónica...oye vale...

Locutora: Está pensando...

Locutor: Está pensando no, que mami le dice que no participe.

Locutora: Así es la democracia...

Locutor: Alejandro, mira...

Niño: Opositor...

Locutora: Opositor dijo. ¡Muy bien, Alejandro!

Locutor: Mira Alejandro, tu materia favorita va a ser la última pregunta y me cuentas por qué te gusta. ¿Cuál es tu materia favorita? ¿Qué te gusta a ti mucho?

Niño: Hacer deportes.

Locutor: Hacer deportes...¿Cuál es tu favorito?

Niño: Fútbol

Locutor: ¡Muy bien! ¡Qué fino!

Locutora: ¿Y quieres ser como Messi o como Ronaldo?

Niño: Ronaldo.

Locutora: Ahhh...gay...bueno...

Locutor: Cónchale vale...esta mujer está alcohólica. Oye vale pero qué esto...

Locutora: Ale, te amo. Dios te bendiga.

Locutor: Dios te bendiga Alejandro. Saludos a tu mamá, a tu papá, a todos en la casa y a todos los niños de Margarita.

Locutor: ya tendrías al niño disfraza'o el primer día de clases.

Locutora: ; Ay sí!...el niño gay que quiere ser como Ronaldo. Bueno, a sacarle las cejitas, vamos a sacarle las cejitas...

Por parte de la enunciadora se revela en el diálogo anterior un alto contenido homofóbico, discriminatorio y machista hacia la comunidad LGBTI que en forma de humor negro intenta ser escondido. Como la enunciadora posee una falta de empatía hacia el gobierno actual, realiza preguntas políticas que no tienen nada que ver con un niño de 7 años. Intenta asociar los bigotes de cualquier persona con los bigotes del mandatario Nicolás Maduro. Podemos ver, por un instante que se produce la quietud de los interlocutores (el niño y su madre) al momento de responder las preguntas, lo que pudo haber ocurrido por problemas de conexión o porque sencillamente perciben que no son preguntas adecuadas. A pesar de la intervención de otro locutor para desviar la atención, la enunciadora continúa en su afán de realizar preguntas fuera de contexto y termina con frases homofóbicas y de una vez juzgando al niño por querer ser como Ronaldo. Afortunadamente, este programa fue sacado del aire por la Comisión Nacional de Telecomunicaciones (CONATEL). La locutora emitió un comunicado en el que lamentó 
lo sucedido y se justificó argumentado que ese era un programa de humor. Son esos los discursos heteronormados o heredados que según Ruiz (2011, p. 217) "estos hechos visibles, no son más que el resultado de esas constantes negociaciones de sentidos que se generan al interior de los discursos instituyentes e instituidos". En ese caso, el discurso instituyente es aquel que ha sido impregnado en la sociedad, como es el de mantener una familia patriarcal con padre, madre e hijos y el discurso instituido es aquel en donde la existencia de otras condiciones diferentes a la heterosexualidad se alejan de los patrones impuestos por Dios y las iglesias católica y cristiana.

Ese lenguaje en su materialidad produjo diferentes sentidos y parece ser un discurso que persiste en los sectores de la población, aunque algunas personas mostraron su rechazo. La presencia de este tipo de discurso pone de manifiesto represiones y falta de respeto hacia la comunidad LGBTI, aun así cuando la Constitución venezolana resalta la no discriminación de personas bajo ningún concepto.

En cuanto a los casos de homofobia, se puede ver que a pesar de que existe respaldo legal y que supuestamente debería ser avalado y respetado por los diversos sectores de la población, especialmente por el gobierno y la oposición, existe un punto de contradicción que es heterogéneo y constitutivo de ese discurso y lo proferido por los sujetos en cuestión. Esto puede verse, también, en opiniones posteriores de la locutora en las que no reconoce totalmente que hizo comentarios homofóbicos y discriminatorios. Significa que ella como sujeto, forma parte de una sociedad cuyos parámetros y formaciones discursivas son dominantes y ya están construidas a favor de la homofobia. Es un discurso que demuestra, de cierta manera, la realidad social.

\section{CONSIDERACIONES FINALES}

Vimos dos casos puntuales que fueron transmitidos por algunos medios de comunicación en Venezuela y provocaron reacciones por parte de la población, demostrando así que existen efectos diversos de sentidos. Esto significa que lo enunciado en estos ejemplos se encuentra en la memoria discursiva o forma parte de la realidad social de los sujetos.

Se revela así, que existe una contradicción y sentidos incompletos del discurso emitido. Una gran diferencia entre lo que está establecido legalmente y la realidad en cuanto a los derechos y deberes de los ciudadanos, sobre todo de la comunidad LGBTI que viene luchando por espacios dentro de la sociedad venezolana.

Si es cierto que en la memoria del venezolano está la poca participación en materia política y que se han producido cambios en la actualidad, el asunto de reconocer los derechos y deberes de la comunidad LGBTI no ha calado en la mayoría de la población, ya que se profieren frases homofóbicas y despectivas desde las altas esferas del gobierno hasta programas radiales, tales como los relatados anteriormente. Lo que nos llevaría a reflexionar y a preguntarnos si realmente estamos a la par de las mudanzas que se dan en el mundo o si todavía mantenemos el esquema impuesto por una sociedad patriarcal y machista. 


\section{REFERENCIAS}

BRACCI, L. Gobierno Venezolano sanciona programa radial "Calma Pueblo". Aquí la razón. Publicado el 25/09/2017. Disponible en https://www.youtube.com/watch?v=GzUnAiXiBYI. Consultado el 27/11/2017.

COMISIÓN ECONÓMICA PARA AMÉRICA LATINA Y EL CARIBE (CEPAL). 2016. Disponible en http://interwp.cepal.org/sisgen/ConsultaIntegrada.asp?IdAplicacion=1\&idTema=362\&idIndicad or $=2280 \&$ idioma $=$ e. Consultado el 28/04/ 2019.

CONSTITUCIÓN DE LA REPÚBLICA BOLIVARIANA DE VENEZUELA (1999, 30 de diciembre). Disponible en http://www.minci.gob.ve/wpcontent/uploads/2011/04/CONSTITUCION.pdf. Consultado el 21/04/2019.

GASPARINI, E. A língua na análise do discurso. Revista da ANPOLL, no 39, p. 62-68, Florianópolis, jul./ago. 2015. Disponible en https://revistadaanpoll.emnuvens.com.br/revista/article/download/904/831. Consultado el 21/04/2019.

GLOBOVISION VIDEOS. Lo que dijo Pedro Carreño en la Asamblea Nacional sobre Capriles y Primero Justicia. Publicado el 13 agosto 2013. Disponible en https://www.youtube.com/watch?v=AvHbOFfHZ7g. Consultado el 27/11/2017.

LEITE, M.A. Encontros e (re) encontros com imagens docentes: uma análise discursiva. Fórum Linguístico, Florianópolis, v. 11, n. 4, 415-422, out./dez. 2014. Disponible en http://dx.doi.org/10.5007/1984-8412.2014v11n4p415. Consultado el 15/04/2019.

PEREIRA, E. O "Cavalo de Tróia" de Michel Pêcheux: uma breve reflexão sobre a análise automática do discurso. Transinformação, Campinas, 19 (3), 207-218, set./dez., 2007. Disponible en http://www.scielo.br/scielo.php?pid=S010337862007000300001\&script=sci abstract\&tlng=pt. Consultado el 21/04/2019.

REYES, Estefanía. Comunidad LGBTI en las sombras: estas son las principales reivindicaciones que aún exige. Noticia al día. Publicado el 28/06/2017. Disponible en http://noticiaaldia.com/2017/06/comunidad-lgbti-en-las-sombras-estas-son-las-principalesreivindicaciones-que-exigen-en-2017/. Consultado el: 23/10/2017.

RUIZ, N. Significaciones imaginarias sociales sobre la homosexualidad en la prensa escrita de Venezuela. Psicoperspectivas, Chile, 10 (2), 202- 223, 2011. Disponible en http://www.psicoperspectivas.cl/index.php/psicoperspectivas/issue/view/15. Consultado el 22/04/2019.

SANTANDER, Pedro. Por qué y cómo hacer análisis de discurso. Cinta Moebio, 41, 207-224, 2011. Disponible en www.moebio.uchile.cl/41/santander.html. Consultado el 21/04/2019.

STECHER, A.; STECHER, L. Identidad y discursos multiculturales en los ensayos de Jamaica Kincaid. Estudios Filológicos, 46, 137-155, 2010. Disponible en https://scielo.conicyt.cl/scielo.php?script=sci_arttext\&pid=S0071-17132010000200008.

Consultado el 21/04/2019.

Artigo recebido em: fev. de 2019.

Aprovado e revisado em: ago. de 2019.

Publicado em: dezembro de 2019. 
Para citar este texto:

MARCANO, Mery Carolina Andrades. Ejemplos del discurso homofóbico emitido por algunos sectores políticos en venezuela: artículo 21 de la constitución nacional. Entremeios [Revista de Estudos do Discurso, ISSN 2179-3514, on-line, www.entremeios.inf.br], Seção Estudos, Programa de Pós-Graduação em Ciências da Linguagem (PPGCL), Universidade do Vale do Sapucaí (UNIVÁS), Pouso Alegre (MG), vol. 19, p. 159-170, jul. - dez. 2019.

DOI: http://dx.doi.org/10.20337/ISSN2179-3514revistaENTREMEIOSvol19pagina159a170 